\title{
Nitrogênio e Azospirillum brasilense no desenvolvimento inicial da cana-de-açúcar
}

\author{
Michaela Carolina Gonçalves, Kátia Cristina da Silva, Carlos Eduardo da Silva Oliveira, Fábio Steiner
}

Universidade Estadual de Mato Grosso do Sul - UEMS, Cassilândia-MS. E-mail: steiner@uems.br

\section{Resumo}

Um estudo foi conduzido com o objetivo de avaliar os efeitos da interação entre a inoculação da muda prébrotada com Azospirillum brasilense e a adubação nitrogenada em cobertura no desenvolvimento das plantas de cana-de-açúcar (Saccharum officinarum). Mudas pré-brotadas de cana-de-açúcar, oriundas de minirrebolos de 3,0 cm de comprimento da variedade RB867515, foram transplantadas aos 25 dias após a brotação para vasos plásticos de $12 \mathrm{~L}$. Os tratamentos foram dispostos em um delineamento de blocos casualizados, em esquema fatorial $2 \times 5$ : dois tratamentos de inoculação [sem (controle) e com inoculação de Azospirillum brasilense] e cinco doses de adubação nitrogenada em cobertura (0, 30, 60, 90 e $120 \mathrm{mg}$ $\mathrm{dm}^{-3}$ de N), com quatro repetições. A inoculação com $A$. brasilense foi realizada no transplantio das mudas com o uso de $4 \mathrm{~mL}$ do inoculante AzoTotal ${ }^{\circ}$ por muda, contendo as estirpes $A_{b V}$ e $A_{b V}$. A adubação nitrogenada em cobertura foi realizada aos 20 dias após o transplantio das mudas na forma de ureia (45\% de $\mathrm{N}$ ). Os resultados reportaram que a aplicação de doses de $\mathrm{N}$ em cobertura resultou no incremento linear da altura de planta, diâmetro de colmo, número de folhas por planta, número de perfilhos e produção de matéria seca das plantas inoculadas com $A$. brasilense. Quando as plantas não foram inoculadas com $A$. brasilense, a adubação nitrogenada resultou apenas no aumento do número de folhas e de perfilhos por planta. $O$ uso da inoculação de $A$. brasilense em mudas de cana-de-açúcar pré-brotadas tem efeito benéfico no desenvolvimento das plantas somente quando associada a adubação nitrogenada em cobertura. As plantas de cana-de-açúcar não adubadas com fertilizante nitrogenado tem resposta negativa à inoculação com $A$. brasilense, indicando a ocorrência de possíveis efeitos fitotóxicos no desenvolvimento das plantas até os 60 dias após o transplantio.

Palavras-chave: adubação nitrogenada; bactérias diazotróficas; fixação biológica de nitrogênio; inoculante; Saccharum officinarum.

\section{Nitrogen and Azospirillum brasilense in the initial development of sugarcane}

\section{Abstract}

A study was conducted with the objective of investigating the effects of the interaction between the inoculation of the pre-sprouted seedlings with Azospirillum brasilense and the nitrogen fertilization in topdressing on the development of sugarcane plants (Saccharum officinarum). Pre-sprouted sugarcane seedlings, produced from $3.0 \mathrm{~cm}$ long mini-stems of the RB867515 variety, were transplanted 25 days after sprouting into $12 \mathrm{~L}$ plastic pots. The treatments were arranged in a randomized block design, in a $2 \times 5$ factorial scheme: two inoculation treatments [without (control) and inoculation with Azospirillum brasilense] and five application rates of $\mathrm{N}$ fertilizer in topdressing $\left(0,30,60,90\right.$ and $120 \mathrm{mg} \mathrm{dm}^{-3}$ of $\mathrm{N}$ ), with four repetitions. The inoculation with $A$. brasilense was carried out in transplanting the seedlings using $4 \mathrm{~mL}$ of the inoculum AzoTotal ${ }^{\circledR}$ per seedling, containing the strains AbV5 and AbV6. The nitrogen fertilization in topdressing was performed at 20 days after transplanting the seedlings as urea (45\% of $N$ ). The results reported that the application of $\mathrm{N}$ fertilizer rates in topdressing resulted in a linear increase in plant height, stem diameter, number of leaves per plant, number of tillers and dry matter production of plants inoculated with $A$. brasilense. When the plants were not inoculated with $A$. brasilense, nitrogen fertilization resulted in an increase also in the number of leaves and tillers per plant. The use of $A$. brasilense inoculation in pre-sprouted sugarcane seedlings has a beneficial effect on the development of plants only when associated with nitrogen fertilization in topdressing. Sugarcane plants not fertilized with $\mathrm{N}$ have a negative response to inoculation with $A$. brasilense, indicating the occurrence of possible phytotoxic effects on plant development up to 60 days after transplanting.

Keywords: nitrogen fertilization; diazotrophic bacteria; biological nitrogen fixation; inoculant; Saccharum officinarum. 


\section{Introdução}

O Brasil é o maior produtor mundial de cana-de-açúcar (Saccharum officinarum), com uma área plantada na ordem de 8,48 milhões de hectares e produção de 643 milhões de toneladas de colmos produzidos na safra 2019/2020 (CONAB, 2020). A produtividade brasileira estimada na safra 2019/2020 foi de 75,8 $\mathrm{Mg} \mathrm{ha}^{-1}$, considerada baixa quando comparada com $\mathrm{O}$ potencial de produção da cultura que é superior à $200 \mathrm{Mg} \mathrm{ha}{ }^{-1}$ (SANTOS; BORÉM, 2013). As condições climáticas adversas e a baixa disponibilidade de nutrientes dos solos tropicais, especialmente de nitrogênio ( $N$ ) têm sido apontados como os principais fatores que contribuem para a baixa produtividade da cultura de cana-de-açúcar no Brasil (PRADO; PANCELLI, 2008; SCHULTZ et al., 2012; ABREU et al., 2013).

$O$ adequado desenvolvimento dos canaviais e a obtenção de altas produtividades de colmos são dependentes do emprego de tecnologias apropriadas, com destaque para o adequado manejo da adubação nitrogenada. $\mathrm{O}$ nitrogênio (N) é requerido em grandes quantidades pelas plantas de cana-de-açúcar. Estima-se que a cultura extrai em torno de $180 \mathrm{~kg}$ $\mathrm{ha}^{-1}$ de $\mathrm{N}$ para produzir $100 \mathrm{Mg} \mathrm{ha}^{-1}$ de colmos (OLIVEIRA et al., 2011). A maior parte desta demanda é atendida pela adubação nitrogenada (PRADO; PANCELLI, 2008; BASTOS et al., 2017), em complementação à quantidade fornecida pelo solo ou pelo processo de fixação biológica de nitrogênio (URQUIAGA et al., 2012; SCHULTZ et al., 2012). A resposta de produtividade da canade-açúcar à adubação nitrogenada depende de diversos fatores que vão desde o material genético até as condições edafoclimáticas (CABRERA; ZUAZNÁBAR, 2010), embora, Pradi e Pancelli (2008) constataram que a cultura tem resposta em produtividade até a dose de $200 \mathrm{~kg}$ $\mathrm{ha}^{-1}$ de $\mathrm{N}$. No entanto, o adequado manejo do $\mathrm{N}$ no sistema solo-planta-palha é normalmente dificultado, devido à variabilidade dos processos de mineralização, lixiviação, volatilização, denitrificação e extração pela cultura.

A adoção de práticas de manejo que possibilite otimizar a extração de $\mathrm{N}$ pela cultura de cana-de-açúcar são importantes para o setor sucroenergético, em razão do alto custo dos fertilizantes nitrogenados e das perdas de $\mathrm{N}$ no sistema solo-planta, que podem representar prejuízos aos agricultores e riscos ao ambiente pela contaminação da água e do solo (UDVARDIA et al., 2015). Nesse sentido, uma alternativa para melhorar a eficiência do uso de $\mathrm{N}$ e, consequentemente, reduzir o uso de fertilizantes nitrogenados na cultura, consiste na utilização de bactérias diazotróficas, capazes de promover a fixação biológica de nitrogênio (FBN) (SCHULTZ et al., 2012; PEREIRA et al., 2013; GÍRIO et al., 2015; OLIVEIRA; SIMÕES, 2016; LOPES et al., 2019).

As bactérias diazotróficas consistem num grupo de microorganismos capazes de converter o nitrogênio $\left(N_{2}\right)$ presente na atmosfera em formas que podem ser assimiláveis pelas plantas $\left(\mathrm{NH}_{3}\right)$, por meio da FBN, processo esse diretamente influenciado pela enzima nitrogenase (SHIN et al., 2016). O gênero Azospirillum é um dos grupos de microorganismos mais estudados para a inoculação em gramíneas de interesse agronômico, destacando-se dentre os grupos de bactérias diazotróficas endofíticas com capacidade de fixação biológica de $\mathrm{N}$ e promover o crescimento das plantas. Estudos tem comprovado a eficiência da inoculação de Azospirillum brasilense na cultura da cana-deaçúcar resultando em maior desenvolvimento e produtividade de colmo (MOUTIA et al., 2010; SERNA-COCK et al., 2011; MOURA et al., 2019).

O Azospirillum brasilense é uma bactéria endofítica gram-negativas, capaz de fixar nitrogênio e colonizar todas as partes da planta, especialmente as raízes de uma ampla variedade de espécies gramíneas (BASHAN; HOLGUIN, 1997). Além da fixação de $N_{2}$ atmosférico, essas bactérias contribuem para maior desenvolvimento das plantas através de diversos mecanismos como a síntese de substâncias promotoras de crescimento, como auxinas, giberelinas e citocininas, aumento da atividade da enzima nitrato redutase, indução da resistências das plantas aos estresses abióticos e bióticos, e a solubilização de fosfatos (FUKAMI et al., 2018).

Estudos realizados comprovam que a resposta dos genótipos à inoculação de $A$. brasilense é dependente das condições edafoclimáticas, sendo mais efetiva em solos de baixa e média fertilidade (OLIVEIRA et al., 2006) e em condições ambientais adversas (MOUTIA et al., 2010). Os ganhos médios decorrentes da FBN no cultivo de cana-de-açúcar no Brasil são em torno de $40 \mathrm{~kg} \mathrm{ha}^{-1}$ de N (URQUIAGA et al., 2012). Neste contexto, a utilização da inoculação com bactérias diazotróficas pode melhorar a 
contribuição da FBN para a produção da cultura de cana-de-açúcar, proporcionando uma agricultura de menor impacto ambiental e mais rentável devido a possibilidade de se reduzir o uso de fertilizantes nitrogenados na cultura. Portanto, torna-se importante compreender a resposta dos genótipos de cana-de-açúcar à inoculação de bactérias endofíticas e o quanto esta prática de manejo poderá reduzir a aplicação de fertilizantes nitrogenados.

O presente estudo foi conduzido com o objetivo de avaliar o efeito da interação entre a inoculação da muda pré-brotada com Azospirillum brasilense e a aplicação de doses de nitrogênio em cobertura no desenvolvimento das plantas de cana-de-açúcar (Saccharum officinarum var. RB867515).

\section{Material e Métodos}

A pesquisa foi realizada em uma casa de vegetação climatizada na Estação Experimental Agronômica na Universidade Estadual de Mato Grosso do Sul - UEMS, em Cassilândia, MS (19005'30" S; 51ㅇ4'50" W e altitude média de $540 \mathrm{~m}$ ), no período de março a maio de 2019. Durante o experimento, as condições ambientais no interior da casa de vegetação foram: temperatura média do ar de $26 \stackrel{\circ}{\circ}$ ( $\pm 2 \stackrel{\circ}{\circ}$ ) e umidade relativa do ar de $68 \%$ ( $\pm 6 \%$ ).

Foram utilizados vasos plásticos com $12 \mathrm{~L}$ de capacidade, preenchidos com $11 \mathrm{dm}^{3}$ de solo arenoso peneirado em malha de $5 \mathrm{~mm}$, proveniente da camada superficial $(0,0-0,20 \mathrm{~m})$ de um Neossolo Quartzarênico Órtico latossólico (NQo), coletado em uma área de pastagem nativa sem histórico de cultivo agrícola. Solo de áreas sem histórico de uso agrícola é considerado ideal para investigar a interação entre a inoculação de bactérias diazotróficas e a aplicação de nitrogênio. As principais características químicas do solo foram as seguintes: $\mathrm{pH}\left(\mathrm{CaCl}_{2}\right)=4,6$, matéria orgânica $=14 \mathrm{~g} \mathrm{dm}^{-3}, \mathrm{P}$ (Mehlich-1) $=7,8$ $\mathrm{mg} \mathrm{dm}, \mathrm{K}=0,16 \mathrm{cmol}_{\mathrm{c}} \mathrm{dm}^{-3}, \mathrm{Ca}=1,50 \mathrm{cmol}_{\mathrm{c}}$ $\mathrm{dm}^{-3}, \mathrm{Mg}=0,50 \mathrm{cmol}_{\mathrm{c}} \mathrm{dm}^{-3}, \mathrm{H}+\mathrm{Al}=3,60 \mathrm{cmol}_{\mathrm{c}}$ $\mathrm{dm}^{-3}, \mathrm{Al}=0,25 \mathrm{cmol}_{\mathrm{c}} \mathrm{dm}^{-3}, \mathrm{CTC}=5,80 \mathrm{cmol}_{\mathrm{c}} \mathrm{dm}^{-3}$ e $\mathrm{V}=38 \%$.

A correção da acidez do solo foi realizada com a aplicação de $1,10 \mathrm{~g}$ de calcário por $\mathrm{dm}^{3}$ de solo ( $\mathrm{CaO}: 38 \%$; $\mathrm{MgO}$ : $11 \%$; e, PRNT: $85 \%$ ), visando elevar a saturação por base do solo a $70 \%$ (SOUSA; LOBATO, 2004). Após a aplicação do calcário, o solo foi homogeneizado, umedecido até alcançar $80 \%$ da capacidade de retenção de água, e incubado por 30 dias. Decorrido esse período, o solo foi fertilizado com $250 \mathrm{mg} \mathrm{dm}^{-3}$ de $P$ (superfosfato triplo), $100 \mathrm{mg} \mathrm{dm}^{-3}$ de $\mathrm{K}$ (cloreto de potássio), $15 \mathrm{mg} \mathrm{dm}{ }^{-3}$ de $\mathrm{S}$ (gesso agrícola), $2 \mathrm{mg} \mathrm{dm}^{-3}$ de Cu (sulfato de cobre), 2 $\mathrm{mg} \mathrm{dm}{ }^{-3}$ de $\mathrm{Zn}$ (sulfato de zinco), $1 \mathrm{mg} \mathrm{dm}^{-3}$ de Mo (molibdato de amônio) e $1 \mathrm{mg} \mathrm{dm}^{-3}$ de $B$ (ácido bórico), seguindo as recomendações de Novais et al. (1991) para ensaios em vasos sob condições de casa de vegetação.

A variedade de cana-de-açúcar utilizada no experimento foi a RB867515, que apresenta crescimento rápido, boa tolerância à seca, alta produtividade agrícola e alto teor de sacarose, além de boa brotação de soqueira. É uma variedade responsiva à inoculação de bactéria diazotróficas (SCHULTZ et al., 2012; PEREIRA et al., 2013; GÍRIO et al., 2015), e, atualmente, representa cerca de $30 \%$ da área de cultivo de cana-de-açúcar da região Centro-Sul do Brasil (SANTOS; BORÉM, 2013).

$O$ delineamento experimental utilizado foi 0 de blocos casualizados, disposto em esquema fatorial $2 \times 5$, com quatro repetições. Os tratamentos foram constituídos por dois tratamentos de inoculação [sem inoculação (controle) e com a inoculação de Azospirillum brasilense] e por cinco doses de adubação nitrogenada em cobertura $(0,30,60,90$ e $120 \mathrm{mg}$ $\mathrm{dm}^{-3}$ de N). Cada unidade experimental foi constituída por um vaso plástico de 12 L contendo uma planta, perfazendo um total de 40 vasos.

A inoculação das mudas com Azospirillum brasilense foi realizada com 0 inoculante comercial líquido AzoTotal (Total Biotecnologia), - qual contém as estirpes $\mathrm{AbV}_{5}$ e $\mathrm{AbV}_{6}$ [concentração mínima de $2,0 \times 10^{8}$ unidades formadoras de colônias (UFC) por $\mathrm{mL}$ ], na dose de $4 \mathrm{~mL}$ do inoculante por muda pré-brotada. $\mathrm{O}$ inoculante foi aplicado sobre as raízes das plantas por ocasião de transplante das mudas para os vasos, com o auxílio de uma pipeta graduada em mililitros. A adubação nitrogenada em cobertura foi realizada aos 20 dias após o transplantio das mudas na forma de ureia ( $45 \%$ de $\mathrm{N}$ ).

$\mathrm{O}$ transplantio das mudas pré-brotadas de cana-de-açúcar para os vasos plásticos foi realizado aos 25 dias após a brotação. Os minirrebolos (segmentos de colmos com gemas individualizadas) de $3,0 \mathrm{~cm}$ de comprimento utilizados para a produção das mudas prébrotadas (MPB) foram extraídos de colmossementes provenientes de um viveiro primário de 10 meses de idade da variedade RB867515, 
localizado na Universidade Estadual de Mato Grosso do Sul (UEMS), em Cassilândia (MS). Os minirrebolos não receberam nenhum tratamento térmico e nem o uso de fungicidas. As mudas prébrotadas foram produzidas em caixas plásticas $(42 \times 28 \times 6 \mathrm{~cm})$, preenchidas com substrato comercial (Carolina Soil ${ }^{\circ}$ ), com as seguintes características: $\mathrm{pH} 5,6 ; 0,85 \mathrm{~g} \mathrm{dm}^{-3}$ de $\mathrm{N} ; 0,18 \mathrm{~g}$ $\mathrm{dm}^{-3}$ de P, 0,25 $\mathrm{g} \mathrm{dm}^{-3}$ de K; $1,24 \mathrm{~g} \mathrm{dm}^{-3}$ de Ca; $0,72 \mathrm{~g} \mathrm{dm}^{-3}$ de $\mathrm{Mg} ; 0,30 \mathrm{~g} \mathrm{dm}^{-3}$ de $\mathrm{S} ; 0,70 \mathrm{dS} \mathrm{m}^{-1}$ de condutividade elétrica (CE); $76 \%$ de porosidade total e $55 \%$ de capacidade de retenção de água. Após o transplantio, todos os tratamentos foram mantidos em condições controladas de casa de vegetação e diariamente irrigados para manter o conteúdo de água próximo à $80 \%$ da capacidade de retenção de água do solo.

Aos 60 dias após o transplantio da canade-açúcar, as plantas foram retiradas dos vasos, e as raízes lavadas em água corrente sobre peneiras com malha de $1,0 \mathrm{~mm}$, para remoção do solo. Em seguida, foram mensuradas as seguintes características morfológicas: altura de planta $(A P)$, diâmetro do colmo (DC), número de folhas por planta (NF), número de perfilhos por vaso (NP), matéria seca da parte aérea (MSPA), matéria seca das raízes (MSR) e matéria seca total (MST).

A altura de planta (AP), em centímetros, foi determinada a partir do nível do solo até a altura de inserção da folha +1 (sistema de numeração de Kuijper), como proposto por Gírio et al. (2015). O diâmetro do colmo (DC), em milímetros, foi mensurado na base do colmo principal (GÍRIO et al., 2015), utilizando um paquímetro digital. A determinação da massa de matéria seca da parte aérea (folhas + colmos) e das raízes foi realizada após a secagem do material em estufa de circulação forçada de ar à $65{ }^{\circ} \mathrm{C}$, por 72 horas (GíRIO et al., 2015), e os resultados expressos em $\mathrm{g} /$ planta. A matéria seca total (MST) foi obtida pela soma de todas as partes da planta (folhas, colmo e raízes).

Os dados foram submetidos à análise de variância (ANOVA), e a significância do efeito da inoculação com Azospirillum brasilense foi testada pelo teste $t$ de Fisher (LSD) ao nível de 5\% de probabilidade. Para as doses de $\mathrm{N}$ em cobertura foram utilizadas a análise de regressão polinomial e as equações significativas (teste $F, p$ $\leq 0,05)$ com os maiores coeficientes de determinação $\left(R^{2}\right)$ foram ajustadas. As análises estatísticas foram realizadas utilizando-se o software Sisvar $^{\circledast}$ versão 5.6 para Windows (FERREIRA, 2011). Os gráficos foram elaborados por meio do pacote estatístico do Microsoft Office Excel ${ }^{\circledR} 2016$ (Microsoft Office 365TM).

\section{Resultados e Discussão}

$A$ análise de variância reportou efeitos significativos $(p \leq 0,05)$ da interação entre os fatores inoculação com $A$. brasilense e aplicação de doses de nitrogênio em cobertura para todas as características morfológicas avaliadas (Tabela 1). Isso indica que as plantas de cana-de-açúcar inoculadas e não inoculadas possuem respostas distintas à adubação nitrogenada em cobertura.

Tabela 1. Resumo da análise de variância para os efeitos da inoculação de Azospirillum brasilense e adubação nitrogenada em cobertura no desenvolvimento das plantas de cana-de-açúcar (Saccharum officinarum var. RB867515)

\begin{tabular}{lccccccc}
\hline \multirow{2}{*}{ Causas de variação } & AP & DC & NFP & NP & MSPA & MSR & MST \\
\cline { 2 - 8 } & 0,045 & 0,452 & 0,377 & 0,832 & 0,853 & 0,669 & 0,821 \\
Bloco & 0,042 & 0,001 & 0,189 & 0,273 & 0,001 & 0,130 & 0,004 \\
Inoculação (I) & 0,330 & 0,314 & 0,009 & 0,001 & 0,001 & 0,984 & 0,285 \\
Nitrogênio (N) & 0,041 & 0,032 & 0,046 & 0,048 & 0,001 & 0,031 & 0,001 \\
Interação I X N & 8,35 & 6,46 & 12,46 & 9,90 & 7,25 & 14,93 & 9,83
\end{tabular}

AP: altura de planta; DC: diâmetro do colmo; NFP: número de folha por planta; NP: Número de perfilho; MSPA: matéria seca da parte aérea; MSR: matéria seca das raízes; MST: matéria seca total.

O aumento da dose de $\mathrm{N}$ em cobertura proporcionou resposta linear crescente à altura das plantas de cana-de-açúcar inoculadas $\operatorname{com} A$. brasilense, ao passo que a altura das plantas não inoculadas não foi afetada significativamente pela adubação nitrogenada em cobertura (Figura
1A). Quando as plantas foram inoculadas com $A$. brasilense, houve incremento de $5,3 \mathrm{~cm}(10 \%)$ à altura das plantas com a aplicação de $120,0 \mathrm{mg}$ $\mathrm{dm}^{-3}$ de $\mathrm{N}$ em cobertura em comparação ao controle não fertilizado com $\mathrm{N}\left(0,0 \mathrm{mg} \mathrm{dm}^{-3}\right)$. Estes resultados indicam que $\mathrm{o}$ maior 
crescimento das plantas de cana-de-açúcar em resposta a adubação nitrogenada em cobertura foi dependente da inoculação das mudas $\operatorname{com} A$. brasilense. Resultados semelhantes foram reportados por Gírio et al. (2015), os quais verificaram que a inoculação de bactérias diazotróficas endofíticas resultou no aumento da altura das plantas de cana-de-açúcar apenas quando esteve associado à aplicação de $100 \mathrm{mg}$ $\mathrm{dm}^{-3}$ de N. Quando a cana-de-açúcar não foi adubada com $\mathrm{N}$, a inoculação de bactérias diazotróficas endofíticas não resultou em resposta positiva no crescimento da parte aérea das plantas. Schultz et al. (2012) concluíram que a inoculação de bactérias diazotróficas endofíticas promoveu incremento no crescimento das plantas da variedade RB867515 similar à aplicação de $120 \mathrm{~kg} \mathrm{ha}^{-1}$ de $\mathrm{N}$.

Figura 1. Efeito das doses de nitrogênio em cobertura na altura de planta (A) e no diâmetro do colmo (B) das plantas de cana-de-açúcar (Saccharum officinarum, cv. RB867515) inoculadas ou não inoculadas com Azospirillum brasilense.

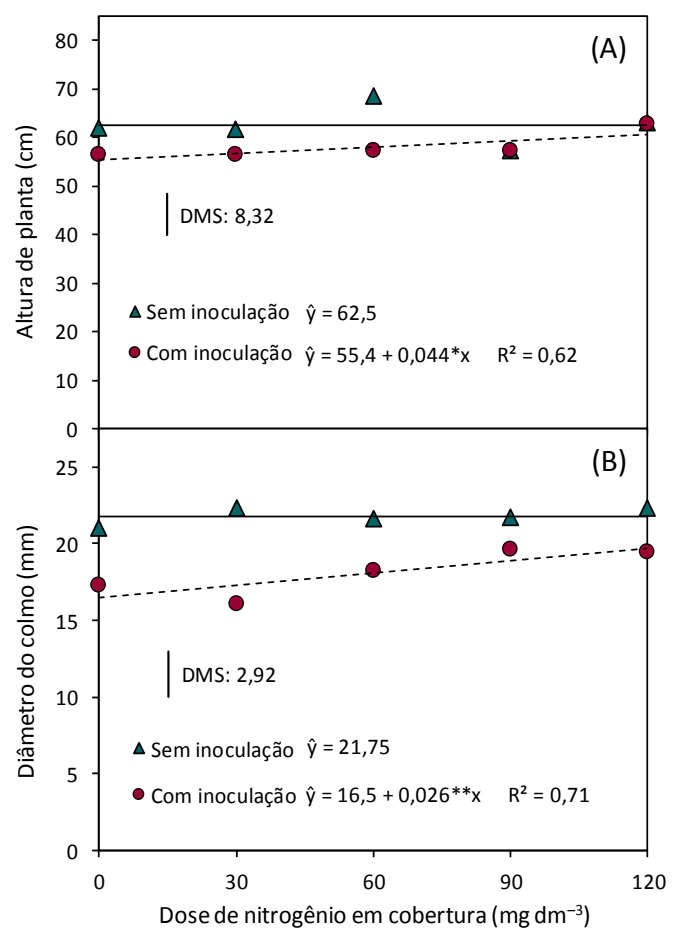

UEMS/Cassilândia, 2019. DMS: diferença mínima significativa do Teste $\mathrm{t}$ de Fisher (Teste LSD). ${ }^{*} \mathrm{e}^{* *}$ : significativo à $5 \%$ e $1 \%$, respectivamente.

O aumento da dose de adubação nitrogenada em cobertura promoveu resposta linear no diâmetro do colmo (DC) das plantas de cana-de-açúcar inoculadas com $A$. brasilense, ao passo que o diâmetro do colmo das plantas não inoculadas não foi afetado pela adubação nitrogenada em cobertura (Figura 1B). Quando as plantas foram inoculadas com $A$. brasilense, houve incremento de $3,1 \mathrm{~mm}(19 \%)$ no DC com a aplicação de $120,0 \mathrm{mg} \mathrm{dm}^{-3}$ de $\mathrm{N}$ em cobertura em comparação ao controle não fertilizado com $\mathrm{N}\left(0,0 \mathrm{mg} \mathrm{dm}^{-3}\right)$. O maior $\mathrm{DC}$ é fator desejável devido à relação direta desta característica com o acúmulo de fotoassimilados e açúcares nos colmos. Oliveira e Simões (2016) reportaram que o menor diâmetro de colmo da cana-de-açúcar foi obtido nas plantas adubadas com fertilizante nitrogenado, ao passo que a inoculação das plantas com bactérias diazotróficas resultou em colmos com maior diâmetro.

A ausência de resposta da altura de planta e diâmetro de colmo à adubação nitrogenada em cobertura pode estar relacionada à baixa resposta da cana-planta à aplicação de $\mathrm{N}$ (SCHULTZ et al., 2012), especialmente devido a intensa dinâmica da matéria orgânica dos solos tropicais e a fixação biológica de $\mathrm{N}$ ocasionada pela capacidade que as plantas de cana-deaçúcar tem de se associar com as bactérias diazotróficas naturalmente encontradas no solo (REIS JÚNIOR et al., 2000; URQUIAGA et al., 2012; LOPES et al., 2019). O solo utilizado neste experimento possuía $14 \mathrm{~g} \mathrm{dm}^{-3}$ de matéria orgânica, e com base nesse valor este solo tinha capacidade de disponibilizar cerca de $84 \mathrm{mg} \mathrm{dm}^{-3}$ de $\mathrm{N}$ às plantas. De acordo com Sousa e Lobato (2004), a capacidade de suprimento de $\mathrm{N}$ do solo a partir da matéria orgânica é de $30 \mathrm{~kg} \mathrm{ha}^{-1}$ (ou seja, $60 \mathrm{mg} \mathrm{dm}^{-3}$ ) para cada $1 \%$ (ou seja, $10 \mathrm{mg}$ $\mathrm{dm}^{-3}$ ) de matéria orgânica. Portanto, verifica-se neste estudo que às respostas ao $\mathrm{N}$ e a interação da inoculação com a adubação nitrogenada possivelmente sofreram influência da matéria orgânica do solo.

O número de folhas por planta foi influenciado significativamente pela inoculação com $A$. brasilense e aplicação de $\mathrm{N}$ em cobertura (Figura 2A). $\mathrm{O}$ aumento da dose de $\mathrm{N}$ em cobertura proporcionou incremento linear no número de folhas nas plantas de cana-de-açúcar. Nas plantas não inoculadas, houve incremento de 4,6 folhas por planta (30\%) com a aplicação de $120,0 \mathrm{mg} \mathrm{dm}^{-3}$ de $\mathrm{N}$ em comparação ao controle não fertilizado com $\mathrm{N}\left(0,0 \mathrm{mg} \mathrm{dm}^{-3}\right)$. Quando as plantas foram inoculadas com $A$. brasilense, houve incremento de 12,5 folhas por planta (96\%) com a aplicação de $120 \mathrm{mg} \mathrm{dm}^{-3}$ de $\mathrm{N}$ em cobertura em comparação ao controle não fertilizado com $\mathrm{N}$. Estes resultados indicam que a 
inoculação com $A$. brasilense resultou em maior incremento no número de folhas por planta quando comparado ao uso isolado apenas da adubação nitrogenada. Resultados semelhantes foram reportados por Gírio et al. (2015), os quais constataram que a inoculação de bactérias diazotróficas endofíticas em mudas pré-brotadas de cana-de-açúcar resultou no incremento do desenvolvimento da parte aérea das plantas até aos 180 dias após o transplantio. Estes resultados comprovam o efeito fisiológico das bactérias diazotróficas na melhoria do crescimento das plantas. Essas bactérias, além de promover a fixação de $\mathrm{N}_{2}$ atmosférico, contribuem para maior desenvolvimento das plantas, especialmente através da síntese de substâncias promotoras de crescimento, como auxinas, giberelinas e citocininas (FUKAMI et al., 2018). Esse aumento no número de folhas torna as plantas mais eficientes no uso da radiação solar e, consequentemente, tem-se um aumento da taxa de fotossíntese e de crescimento das plantas (OLIVEIRA et al., 2006).

O número de perfilhos por planta foi influenciado significativamente pela inoculação com $A$. brasilense e aplicação de $\mathrm{N}$ em cobertura (Figura 2B). O aumento da dose de $\mathrm{N}$ em cobertura resultou no incremento linear do número de perfilhos nas plantas de cana-deaçúcar. Nas plantas não inoculadas, houve incremento de 0,9 perfilho por planta (21\%) com a aplicação de $120,0 \mathrm{mg} \mathrm{dm}^{-3}$ de $\mathrm{N}$ em comparação ao controle não fertilizado com $\mathrm{N}$ $\left(0,0 \mathrm{mg} \mathrm{dm}^{-3}\right)$. Quando as plantas foram inoculadas com $A$. brasilense, houve incremento de 3,5 perfilhos por planta $(127 \%)$ com a aplicação de $120,0 \mathrm{mg} \mathrm{dm}^{-3}$ de $\mathrm{N}$ em comparação ao controle não fertilizado com N. Avaliando a interação da inoculação de $A$. brasilense e da adubação nitrogenada no crescimento inicial da cana-de-açúcar, Gírio et al. (2015) também mostraram que a inoculação de bactérias diazotróficas quando associada à aplicação de $\mathrm{N}$ resultou na maior emissão de perfilhos por planta. Resultados semelhantes foram reportados por Oliveira e Simões (2016), os quais constataram aumento no número de perfilhos aos 90 dias após o transplantio das plantas de cana-de-açúcar inoculadas com bactérias diazotróficas.

O maior incremento do número de folhas e do número de perfilhos por planta associado ao uso de inoculante contendo $A$. brasilense está relacionado a capacidade dessa bactéria diazotrófica de fixar o $\mathrm{N}_{2}$ atmosférico, produzir substâncias que possuem relação com 0 crescimento vegetal, como os fitormônios auxina, citocinina e giberelina, aumentar a atividade da enzima nitrato redutase e solubilizar fosfatos do solo (PEREIRA et al., 2013; LOPES et al., 2019; FUKAMI et al., 2018). Quando absorvido pelas plantas, o $\mathrm{N}$ aumenta a atividade do meristema apical, promovendo maior taxa de emissão de folhas e maior de perfilhamento das plantas de cana-de-açúcar. Esse aumento no número de folhas e de perfilhos torna as plantas mais eficientes no uso da radiação solar e, como consequência, tem-se um aumento da taxa de crescimento das plantas e maior produção de matéria seca das plantas (OLIVEIRA et al., 2006). Esses resultados reportam a importância do uso da inoculação de $A$. brasilense em associação a adubação nitrogenada. Diversos estudos mostraram que a inoculação de bactérias diazotróficas endofíticas possibilitam a redução no uso de fertilizantes nitrogenados na cultura da cana-de-açúcar (SCHULTZ et al., 2012; PEREIRA et al., 2013; GíRIO et al., 2015; LOPES et al., 2019).

Figura 2. Efeito das doses de nitrogênio em cobertura no número de folhas $(A)$ e no número de perfilhos (B) das plantas de cana-de-açúcar (Saccharum officinarum, cv. RB867515) inoculadas ou não inoculadas com Azospirillum brasilense.

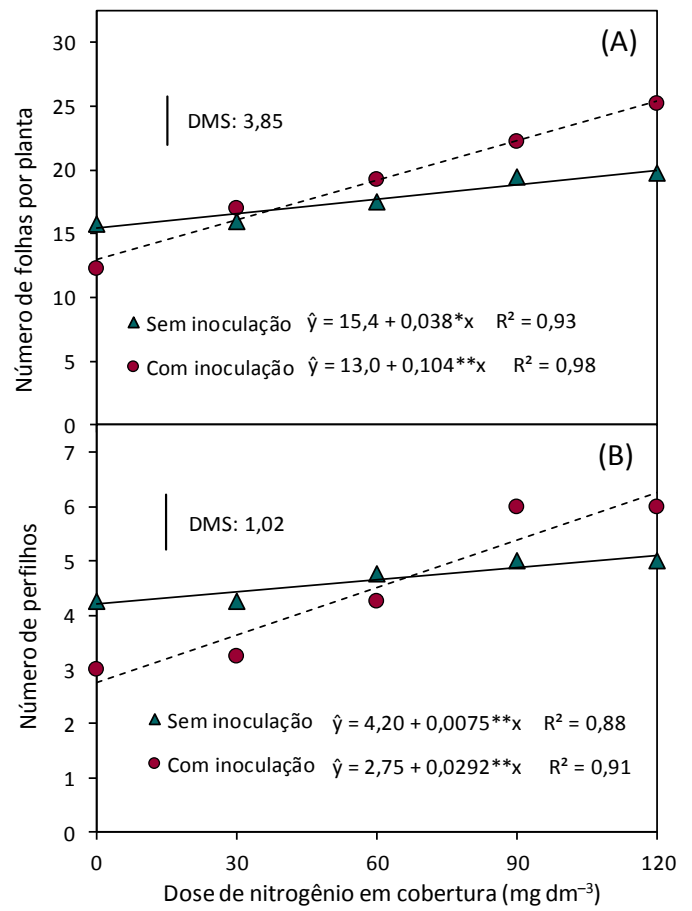

UEMS/Cassilândia, 2019. DMS: diferença mínima significativa do Teste $\mathrm{t}$ de Fisher (Teste LSD). ${ }^{*} \mathrm{e}^{* *}$ : significativo à $5 \%$ e $1 \%$, respectivamente. 
A produção de matéria seca da parte aérea, das raízes e total foi significativamente afeta pela inoculação com $A$. brasilense e aplicação de $\mathrm{N}$ em cobertura (Figura 3 ). O aumento da dose de $\mathrm{N}$ em cobertura proporcionou resposta linear na matéria seca da parte aérea (MSPA) das plantas inoculadas com A. brasilense, ao passo que a MSPA das plantas não inoculadas não foi afetada significativamente pela adubação nitrogenada (Figura 3A). Quando as plantas foram inoculadas com $A$. brasilense, houve incremento de $30,4 \mathrm{~g} /$ planta (132\%) na MSPA com a aplicação de $120,0 \mathrm{mg} \mathrm{dm}^{-3}$ de $\mathrm{N}$ em cobertura em comparação ao controle não adubado com $\mathrm{N}\left(0,0 \mathrm{mg} \mathrm{dm}^{-3}\right)$. Estes resultados indicam que o maior crescimento da parte aérea das plantas de cana-de-açúcar em resposta a adubação nitrogenada em cobertura foi dependente da inoculação das mudas com $A$. brasilense. Resultados semelhantes foram reportados por Gosal et al. (2012), os quais reportaram que o uso de inoculante contendo bactérias diazotróficas resultou no maior acúmulo de matéria seca da parte aérea apenas quando combinado com a adubação nitrogenada. Gírio et al. (2015) também reportaram que o maior crescimento e produção de matéria seca da parte aérea da variedade RB867515 esteve associado ao uso combinado da inoculação de bactérias diazotróficas e da adubação nitrogenada.

$\mathrm{O}$ aumento da dose de $\mathrm{N}$ em cobertura reduziu linearmente a produção de matéria seca das raízes das plantas não inoculadas com $A$. brasilense, ao passo que a matéria seca das raízes das plantas na presença de $A$. brasilense aumentou linearmente com as doses de adubação nitrogenada (Figura 3B). Nas plantas não inoculadas, houve redução de $18,2 \mathrm{~g} /$ planta (40\%) com a aplicação de $120,0 \mathrm{mg} \mathrm{dm}^{-3}$ de $\mathrm{N}$ em comparação ao controle não fertilizado com $\mathrm{N}$ $(0,0 \mathrm{mg} \mathrm{dm})$. Quando as plantas foram inoculadas com $A$. brasilense, houve incremento de $13,6 \mathrm{~g} /$ planta (56\%) com a aplicação de 120,0

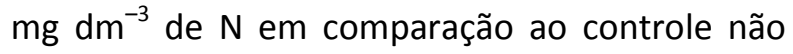
fertilizado com N. A menor produção de matéria secas das raízes das plantas não inoculadas com A. brasilense em reposta à aplicação de doses de $\mathrm{N}$ em cobertura é explicado pelo metabolismo fisiológico da planta. Em solo que o $\mathrm{N}$ não é limitante, a planta reduz a translocação de fotoassimilados e energia (ATP) para a produção de novas raízes, e direciona estes compostos orgânicos para a melhoria do crescimento e desenvolvimento da parte aérea da planta (TAIZ et al., 2017). Por sua vez, o incremento da produção de matéria seca das raízes das plantas inoculadas com $A$. brasilense em reposta à aplicação de doses de $\mathrm{N}$ é explicado pelo efeito fisiológico dessa bactéria diazotrófica no balanço hormonal das plantas, a qual tem capacidade de melhor o crescimento das raízes por meio da síntese de hormônios vegetais (FUKAMI et al., 2018), especialmente a auxina, que tem grande efeito no desenvolvimento do sistema radicular (TAIZ et al., 2017).

Figura 3. Efeito das doses de nitrogênio em cobertura na produção de matéria seca da parte aérea $(A)$, matéria seca das raízes (B) e matéria seca total (C) das plantas de cana-de-açúcar (Saccharum officinarum, cv. RB867515) inoculadas ou não inoculadas com Azospirillum brasilense.

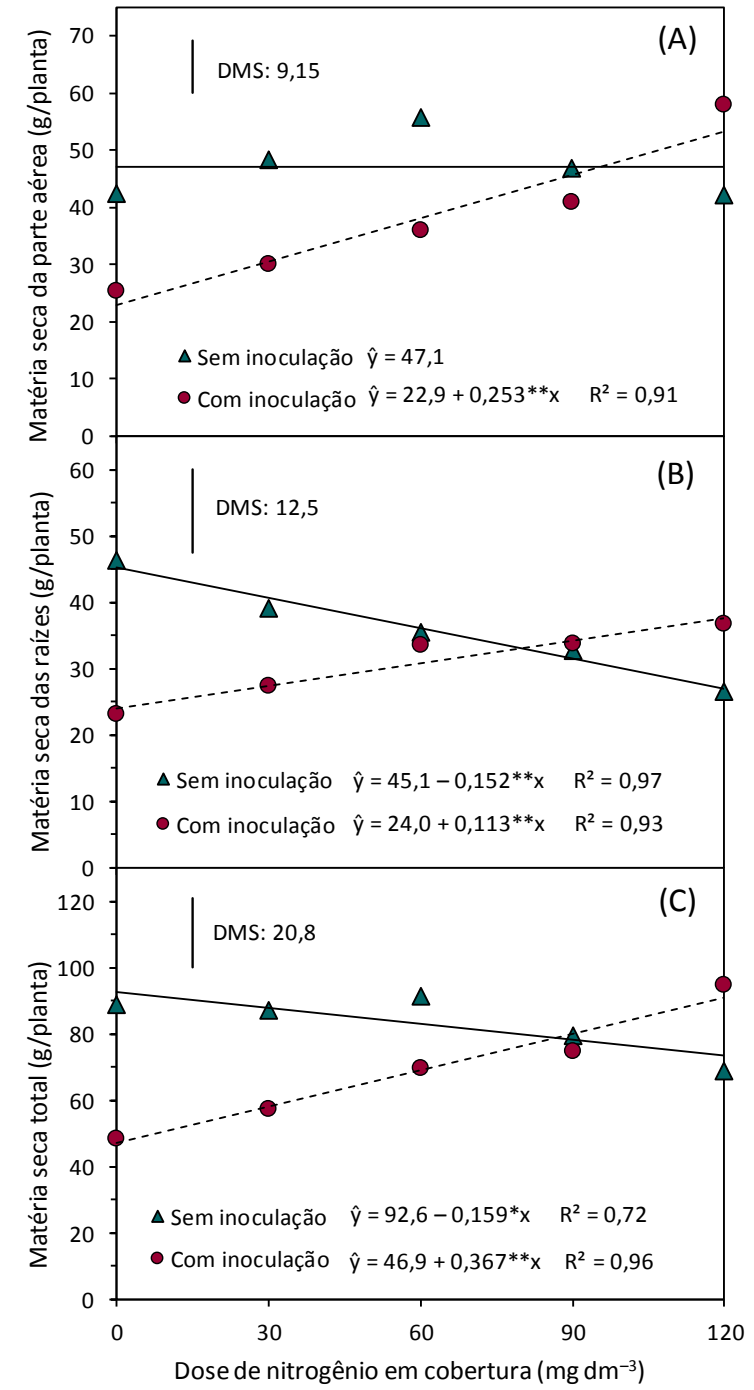

UEMS/Cassilândia, 2019. DMS: diferença mínima significativa do Teste $\mathrm{t}$ de Fisher (Teste LSD). * $\mathrm{e}^{* *}$ : significativo à $5 \%$ e $1 \%$, respectivamente. 
A produção de matéria seca total, reflete a produção de matéria seca das raízes (Figura 3 ). $\mathrm{O}$ aumento da dose de $\mathrm{N}$ em cobertura reduziu linearmente a produção de matéria seca total das plantas não inoculadas com $A$. brasilense, ao passo que a matéria seca total das plantas inoculadas com $A$. brasilense aumentou linearmente com as doses de adubação nitrogenada (Figura 3C). A aplicação de $120,0 \mathrm{mg}$ $\mathrm{dm}^{-3}$ de $\mathrm{N}$ em cobertura resultou na redução de $21 \%$ e no aumento de $94 \%$ na produção de matéria seca das plantas não inoculadas e inoculadas com $A$. brasilense, respectivamente, quando comparado ao controle não adubado com $\mathrm{N}\left(0,0 \mathrm{mg} \mathrm{dm}^{-3}\right)$. Esses resultados reportam a importância do uso do inoculante contendo $A$. brasilense para potencializar o desenvolvimento das plantas e reduzir o uso de fertilizantes nitrogenadas e os custos de produção da canade-açúcar da região do Cerrado. Avaliando a eficiência da inoculação em duas variedades de cana-de-açúcar, Schultz et al. (2012) reportaram que o desenvolvimento das plantas da variedade RB867515 quando inoculada com A. brasilense foi semelhante ao uso de $120 \mathrm{~kg} \mathrm{ha}^{-1}$ de $\mathrm{N}$. No entanto, em experimento conduzido por Gírio et al. (2015), os autores reportaram que a inoculação de bactéria diazotróficas resultou na maior produção de matéria seca total das plantas de cana-de-açúcar apenas quando esteve associado à adubação nitrogenada, confirmando os resultados apresentados neste estudo. Esses resultados reportam a importância do uso da inoculação de $A$. brasilense em associação a adubação nitrogenada.

A inoculação com $A$. brasilense resultou no menor diâmetro de colmo (Figura 1B), número de perfilhos por planta (Figura 2B) e menor produção de matéria seca da parte aérea, das raízes e total (Figura 3 ) das plantas de cana-deaçúcar adubadas com as menores doses de $\mathrm{N}$ em cobertura quando comparado as plantas que não foram inoculadas. Estes resultados sugerem que o uso de $4 \mathrm{~mL}$ do inoculante contendo $A$. brasilense por muda pré-brotada de cana-deaçúcar resultou em efeitos fitotóxicos para o adequado desenvolvimento da cultura até os 60 dias após o transplantio. Portanto, novos experimentos devem ser realizados para verificar a melhor dose de inoculante que deve ser aplicada às mudas pré-brotadas de cana-deaçúcar. Estes estudos poderão mostrar a viabilidade de aplicação da tecnologia na implantação da cultura de cana-de-açúcar, gerando economia para os agricultores e benefícios ambientais para o Brasil.

\section{Conclusões}

O uso da inoculação de Azospirillum brasilense em mudas de cana-de-açúcar prébrotadas tem efeito benéfico no desenvolvimento das plantas somente quando associada a adubação nitrogenada em cobertura.

As plantas de cana-de-açúcar não adubadas com fertilizante nitrogenado tem resposta negativa à inoculação com Azospirillum brasilense.

\section{Referências}

ABREU, M. L.; SILVA, M. A.; TEODORO, I.; HOLANDA, L. A.; SAMPAIO-NETO, G. D. Crescimento e produtividade de cana-de-açúcar em função da disponibilidade hídrica dos Tabuleiros Costeiros de Alagoas. Bragantia, v. 72, n.3, p.262-270, 2013. https://doi.org/10.1590/brag.2013.028

BASHAN, Y.; HOLGUIN, G. Azospirillum-plant relationships: environmental and physiological advances. Canadian Journal of Microbiology, v.43, n.2, p.103-121, 1997. https://doi.org/10.1139/m97-015

BASTOS, A.; TEODORO, J.; TEIXEIRA, M.; SILVA, E.; COSTA, D.; BERNARDINO, M. Efeitos da adubação nitrogenada e potássica no crescimento da cultura da cana-de-açúcar segunda soca. Revista de Ciências Agrárias, v. 40, n. 3, p. 554-563, 2017. https://doi.org/10.19084/RCA17052

CABRERA, J. A.; ZUAZNÁBAR, R. Respuesta de la caña de azúcar a la fertilización nitrogenada en un experimento de larga duración con 24 cosechas acumuladas. Cultivos Tropicales, v. 31, n. 1, p. 93-100, 2010.

CONAB. Acompanhamento da safra brasileira: cana-de-açúcar, Safra 2019/2020. v. 6, n. 3, 58p. Disponível em: https://www.conab.gov.br/infoagro/safras/cana. Acesso em: mar. 2020.

FERREIRA, D. F. Sisvar: a computer statistical analysis system. Ciência e Agrotecnologia, v. 35, n.6, p.1039-1042, 2011. $\underline{70542011000600001}$ 
FUKAMI, J.; CEREZINI, P.; HUNGRIA, M. Azospirillum: benefits that go far beyond biological nitrogen fixation. AMB Express, v. 8, n. 73, p.1-12, 2018. https://doi.org/10.1186/s13568-018-0608-1

GÍRIO, L. A. S.; DIAS, F. L. F.; REIS, V. M.; URQUIAGA, S.; SCHULTZ, N.; BOLONHEZI, D.; MUTTON, M. A. Bactérias promotoras de crescimento e adubação nitrogenada no crescimento inicial de cana-de-açúcar proveniente de mudas pré-brotadas. Pesquisa Agropecuária Brasileira, v. 50, n. 1, p. 33-43, $2015 . \quad$ http://dx.doi.org/10.1590/S0100$\underline{204 \times 2015000100004}$

GOSAL, S.K.; KALIA, A.; UPPAL, S. K.; KUMAR, R.; WALIA, S. S.; SINGH, K.; SINGH, H. Assessing the benefits of Azotobacter bacterization in sugarcane: a field appraisal. Sugar Tech, v.14, p.61-67, 2012. https://doi.org/10.1007/s12355$\underline{011-0131-z}$

LOPES, V. R.; BESPALHOK-FILHO, J. C.; FIGUEIREDO, G. G. O.; OLIVEIRA, R.A.; DAROS, E. Interaction between sugarcane families and plant growth-promoting bacteria in two crop cycles. Semina: Ciências Agrárias, v. 40, n. 2, p. 527-538, 2019. https://doi.org/10.5433/16790359.2019v40n2p527

MOURA, J. B.; SOUZA, R. F.; VENTURA, M. V. A.; FURQUIM, L. C.; VIEIRA-JUNIOR, W. G.; BRAGA, A. P. M.; LIMA, I. R.; CAIXETA, J. G. A.; MILK, D. C.; SILVA, J. C.; ROCHA, E. C. V.; LOPES, H. P. B. Influence of nitrogen fixing bacteria in the establishment of pre-broken sugar cane. Asian Journal of Microbiology, Biotechnology and Environmental Sciences, v. 21, n. 1, p. 22-26, 2019.

MOUTIA, J. F. Y.; SAUMTALLY, S.; SPAEPEN, S.; VANDERLEYDEN, J. Plant growth promotion by Azospirillum sp. in sugarcane is influenced by genotype and drought stress. Plant and Soil, v.337, p.233-242, 2010. https://doi.org/10.1007/s11104-010-0519-7

NOVAIS, R. F.; NEVES, J. C. L.; BARROS, N. F. Ensaio em ambiente controlado. In: OLIVEIRA, A. J.; GARRIDO, W. E.; ARAÚJO, J. D.; LOURENÇO, S. (Eds). Métodos de pesquisa em fertilidade do solo. Brasília: Embrapa-SEA, 1991. p. 189-254.
OLIVEIRA, A. L. M.; CANUTO, E. L.; URQUIAGA, S.; REIS, V. M.; BALDANI, J. I. Yield of micropropagated sugarcane varities in diferente soil types following inoculation with endophytic diazotrophic bacteria. Plant and Soil, v. 284, n. 1, p. 23-32, 2006. https://doi.org/10.1007/s11104006-0025-0

OLIVEIRA, A. R.; SIMÕES, W. L. Cultivares de canade-açúcar inoculadas com bactérias diazotróficas em condições irrigadas no semiárido brasileiro. Revista Energia na Agricultura, v. 31, n. 2, p. 154161, 2016. https://doi.org/10.17224/EnergAgric.2016v31n2p $\underline{154-161}$

OLIVEIRA, E. C. A.; FREIRE, J. F.; OLIVEIRA R. I.; OLIVEIRA, A. C.; FREIRE M. B. G. S. Acúmulo e alocação de nutrientes em cana-de-açúcar. Revista Ciência Agronômica, v. 42, n. 3, p. 579588, 2011.

PEREIRA, W.; LEITE, J. M.; HIPÓLITO, G. S.; SANTOS, C. L. R.; REIS, V. M. Acúmulo de biomassa em variedades de cana-de-açúcar inoculadas com diferentes estirpes de bactérias diazotróficas. Revista Ciência Agronômica, v. 44, n.2, p.363-370, 2013. https://doi.org/10.1590/S1806$\underline{66902013000200020}$

PRADO, R. M.; PANCELLI, M. A. Resposta de soqueiras de cana-de-açúcar à aplicação de nitrogênio em sistema de colheita sem queima. Bragantia, v.67, n.4, p.951-959, 2008. https://doi.org/10.1590/S0006-

$\underline{87052008000400018}$

REIS JÚNIOR, F. B.; SILVA, L. G.; REIS, V. M.; DÖBEREINER, J. Ocorrência de bactérias diazotróficas em diferentes genótipos de canade-açúcar. Pesquisa Agropecuária Brasileira, v.35, n.5, p.985-994, 2000. http://dx.doi.org/10.1590/S0100$\underline{204 \times 2000000500016}$

SANTOS, F.; BORÉM, A. (Ed.). Cana-de-açúcar: do plantio à colheita. Viçosa: Universidade Federal de Viçosa, 2013.

SCHULTZ, N.; MORAIS, R. F.; SILVA, J. A.; BAPTISTA, R. B.; OLIVEIRA, R. P.; LEITE, J. M.; PEREIRA, W.; CARNEIRO JÚNIOR, J. B.; ALVES, B. J. R.; BALDANI, J. I.; BODDEY, R. M.; URQUIAGA, S.; 
REIS, V. M. Avaliação agronômica de duas variedades de cana-de-açúcar inoculadas com bactérias diazotróficas e adubadas com nitrogênio. Pesquisa Agropecuária Brasileira, v.47, p.261-268, 2012. http://dx.doi.org/10.1590/S0100$\underline{204 X 2012000200015}$

SERNA-COCK, L.; ARIAS-GARCÍA, C.; HERNANDEZ, L. J. V. Efecto de la biofertilización sobre el crecimiento en maceta de plantas de caña de azúcar (Saccharum officinarum). Biotecnología en el Sector Agropecuario y Agroindustrial, v. 9, n. 2, p. 85-95, 2011.

SHIN, W.; ISLAM, R.; BENSON, A.; JOE, M. M.; KIM, K.; GOPAL, S.; SAMADDAR, S.; BANERJEE, S.; $S A, T$. Role of diazotrophic bacteria in biological nitrogen fixation and plant growth improvement. Korean Journal of Soil Science and Fertilizer, v.49, n.1, p.17-29, 2016. https://doi.org/10.7745/KJSSF.2016.49.1.017

SOUSA, D. M. G.; LOBATO, E. Cerrado: correção do solo e adubação. 2. ed. Brasília: Embrapa Informação Tecnológica, 2004. 416 p.

TAIZ, L.; ZEIGER, E.; MOLLER, I.; MURPHY, A. Fisiologia e desenvolvimento vegetal. 6 . ed. Porto Alegre: Artmed, 2017. 888 p.

UDVARDIA, M.; BRODIE, EOIN L.; RILEY, W.; KAEPPLER, S.; LYNCH, J. Impacts of agricultural nitrogen on the environment and strategies to reduce these impacts. Procedia Environmental Sciences, v.29, v.3, p.303-318, 2015. https://doi.org/10.1016/j.proenv.2015.07.275

URQUIAGA, S.; XAVIER, R.; MORAIS, R. F.; BATISTA, R.; SCHULTZ, N.; LEITE, J. M.; RESENDE, A.; ALVES, B. J. R.; BODDEY, R. M. Evidence from field nitrogen balance and $15 \mathrm{~N}$ natural abundance data of the contribution of biological $\mathrm{N}_{2}$ fixation to Brazilian sugarcane varieties. Plant and Soil, v.356, p.5-21, 2012. https://doi.org/10.1007/s11104-011-1016-3 